\section{Clinical use of the $\beta_{3}$ adrenoceptor agonist mirabegron in patients with overactive bladder syndrome}

\author{
Monika Vij and Marcus J. Drake
}

Ther Adv Urol

2015, Vol. 7(5) 241-248

DOI: 10.1177/

1756287215591763

(c) The Author(s), 2015.

Reprints and permissions: http://www.sagepub.co.uk/ journalsPermissions.nav

\begin{abstract}
Mirabegron is a $\beta_{3}$ adrenoceptor agonist licensed for the treatment of overactive bladder symptoms, such as urinary urgency or urgency incontinence. $\beta_{3}$ adrenoceptor activation causes detrusor muscle relaxation, but mirabegron may also act by binding other targets in the bladder, and it may also reduce activity in sensory nerves. Phase III clinical trials (SCORPIO, ARIES, and CAPRICORN) evaluated mirabegron at various doses, demonstrating reduction from baseline to endpoint in mean incontinence episodes and mean number of micturitions per $24 \mathrm{~h}$ (coprimary endpoints), along with health-related quality of life and a range of secondary measures. Efficacy was seen in many patients who had previously discontinued antimuscarinic therapy on the grounds of lack of efficacy or poor tolerability. Treatment emergent adverse effects were documented in a long-term study (TAURUS), mostly being of mild or moderate severity. The most frequent adverse effects were hypertension, dry mouth, constipation, and headache, with a lower incidence of dry mouth than for the antimuscarinic active comparator. Efficacy and safety are not substantially different in older patients. A urodynamic safety study in men showed no consistent effect on voiding function, but a small increase in postvoid residual. Use of mirabegron in combination with $\alpha$-adrenergic blockers does not appear to increase adverse effects. Dose reduction is needed in people with severe renal failure, or moderate hepatic failure. Dose adjustment is not needed in relation to food intake. Ongoing research is evaluating the potential for combination therapy with antimuscarinics.
\end{abstract}

Keywords: mirabegron, beta-3 agonist, overactive bladder, LUTS, urinary urgency, urgency urinary incontinence

\section{Introduction}

Lower urinary tract symptoms (LUTS) affecting urine storage include urinary urgency, urgency incontinence, increased daytime frequency and nocturia [Abrams et al. 2002]. Overactive bladder syndrome $(\mathrm{OAB})$ is defined by the International Continence Society as urinary urgency, with or without urgency incontinence, usually with increased daytime frequency and nocturia in the absence of proven infection or any other pathology [Drake, 2014]. It is a chronic symptom complex that can substantially impair quality of life. The prevalence of LUTS [Coyne et al. 2009], OAB and urgency urinary incontinence is substantial, affecting both women and men, and resulting in considerable morbidity, personal cost and health economic burden [Coyne et al. 2014; Milsom et al. 2014].
Initial management uses conservative measures, such as fluid advice and bladder training [Lucas et al. 2012]. Drug therapy using antimuscarinics has long been the mainstay of the pharmacological treatment of OAB [Chapple et al. 2008; Kaplan et al. 2011; Lucas et al. 2012]. However, compliance with these drugs is generally poor [Wagg et al. 2012], due to perceived lack of efficacy and potential high rate of side effects. The emergence of new drugs and treatment regimens should improve patient persistence with treatment and acceptability. Development of mirabegron (YM178), a $\beta_{3}$-adrenoceptor (AR) agonist now offers a new pharmacotherapy option for the treatment of OAB [Maman et al. 2014]. Mirabegron is available for clinical use as a modified release film-coated tablet in an oral controlled
Correspondence to: Marcus J. Drake, DM, MA, FRCS (Urol) University of Bristol, Southmead Hospital, Bristol BS9 1BQ, UK marcus.drakeabui.ac.uk Monika Vij, MS, MRCOG Southmead Hospital, Bristol, UK 
absorption system (OCAS), with two licensed dosage strengths of 25 and $50 \mathrm{mg}$.

\section{Mechanism of action}

There are three subtypes of $\beta-A R$, with the $\beta_{3}$-AR predominating in the detrusor muscle of some species [Ochodnicky et al. 2013], including the human bladder. $\beta_{3}$-AR constitutes a high proportion of the $\beta$-AR mRNA in the human detrusor [Igawa et al. 2010]. Activation of these receptors elicits detrusor relaxation in bladder strips from various species [Takasu et al. 2007], through generation of cyclic adenosine monophosphate [Takasu et al. 2007; Limberg et al. 2010]. $\beta_{3}$-AR may also be present in other cell types of the bladder, such as urothelium [Otsuka et al. 2008; Limberg et al. 2010; Kullmann et al. 2011] or interstitial cells [Limberg et al. 2010]. However, the role of their activation in the urothelium remains to be established [Moro et al. 2013].

In animal studies, activation of $\beta_{3}$-AR gives dosedependent detrusor relaxation during the storage phase of the micturition cycle. Functionally, it increases intervoid interval and bladder compliance, while preserving voiding function in a rodent model [Sadananda et al. 2013]. $\beta_{3}$-AR are also suggested to inhibit sensory nerve activation, including activity in mechanosensitive A- $\delta$ fibers [Aizawa et al. 2010], and also reducing autonomous nonvoiding contractions [Woods et al. 2001; Aizawa et al. 2010; Sadananda et al. 2013]. $\beta$-AR activation can elicit release of nitric oxide by urothelium, giving a potential indirect mechanism which could further contribute to bladder relaxation [Murakami et al. 2007; Yamaguchi and Chapple, 2007]. A critical influence of $\beta_{3}$-ARs in increasing bladder capacity, without changing micturition pressure or residual volume, may be mediated by inhibition of afferent nerve fiber activity [Kanai et al. 2011].

\section{Pharmacokinetics}

The marketed formulation of mirabegron is in an OCAS, with oral bioavailability in the range of 24-53\% [Kashyap and Tyagi, 2013]. The plasma protein binding is $71 \%$ [Dickinson et al. 2013]. The time to reach maximum concentration after dosing is $3-4 \mathrm{~h}$, and the terminal elimination halflife is approximately $50 \mathrm{~h}$. The absolute bioavailability is dose-dependent and affected by gender [Kashyap and Tyagi, 2013]. Interactions with cytochrome P450 (CYP) metabolism [Lee et al. 2013a; Krauwinkel et al. 2014] are potentially relevant clinically. example, drug-drug interactions may occur with concomitant administration of drugs that exert inducible (rifampin) or inhibitory (ketoconazole) effects on CYP3A4/5 [Kashyap and Tyagi, 2013]. CYP2D6 inhibition by mirabegron might alter the plasma exposure of metoprolol [Kashyap and Tyagi, 2013]. One study has shown that combining mirabegron with an $\alpha$-adrenergic antagonist (tamsulosin) did not affect safety aspects, notably cardiovascular adverse effects, in 48 healthy men aged 44 years or older [van Gelderen et al. 2014].

Mirabegron OCAS tablets show a decrease in mirabegron plasma exposure with food that is independent of dose ( 50 or $100 \mathrm{mg}$ ) or sex, but dependent on meal composition; however, this does not warrant dose adjustment in clinical practice [Lee et al. 2013b]. Pharmacokinetic changes observed in subjects with severe renal impairment or moderate hepatic impairment [Dickinson et al. 2013] mean that dose reduction is necessary.

\section{Clinical evidence of efficacy}

Mirabegron has been studied extensively, with more than 10,000 subjects involved in research studies over approximately 10 years. The safety and efficacy was evaluated in five global trials (two in phase II and three in phase III) comparing various doses of mirabegron, either with placebo or tolterodine.

BLOSSOM was a phase II proof of concept trial conducted in six European countries [Chapple et al. 2013a]. The study randomized subjects to mirabegron at doses of 100 or $150 \mathrm{mg}$ twice daily, placebo (twice daily), or tolterodine $4 \mathrm{mg}$ extended release (ER) once daily for 4 weeks. The primary endpoint was change from baseline to end of treatment in mean number of micturition episodes per $24 \mathrm{~h}$. Mirabegron was superior to placebo and tolterodine, with mean reductions in micturition frequency of $2.2,1.2$, and 1.5 , respectively. Mirabegron was superior to placebo in terms of mean volume voided, mean number of incontinence episodes, nocturia episodes and urgency episodes in $24 \mathrm{~h}$. There was no significant difference found between 100 and $150 \mathrm{mg}$ twice daily doses.

The DRAGON study was a 12 -week phase IIB dose-ranging study conducted predominantly in Europe [Chapple et al. 2013b]. A total of 919 patients were randomized in six arms: placebo, mirabegron at doses of $25,50,100$, or $200 \mathrm{mg}$ 
once daily, or tolterodine as an active comparator. A dose-dependent decrease in mean number of micturitions per $24 \mathrm{~h}$ was seen with mirabegron, which was significant at the doses of $50 \mathrm{mg}$ and above compared with placebo. Twenty-eight percent of people receiving mirabegron $50 \mathrm{mg}$ were classified as 'responders' in terms of a reduction in voiding frequency (down to eight times daily or less). This compared with $19 \%$ for placebo and $19 \%$ for tolterodine. There were also significant improvements seen in secondary endpoints, such as mean number of urgency and urgency incontinence episodes, nocturia, and mean voided volume. Responses were evident at 1 week of treatment, with maximum efficacy gained at 8-12 weeks.

The phase III development program comprised three studies: SCORPIO, ARIES, and CAPRICORN. These were large-scale, 12-week, multicenter, randomized, double-blind, parallelgroup studies undertaken in Europe, Australia, and North America. They looked at two coprimary efficacy endpoints: the change from baseline to endpoint in mean incontinence episodes and mean number of micturitions per $24 \mathrm{~h}$. The study populations were adults of at least 18 years of age, with at least eight micturitions per $24 \mathrm{~h}$, and at least three urgency episodes in their 3-day bladder diary, with or without urgency incontinence. Different doses of mirabegron were compared with placebo, and an active antimuscarinic comparator in some studies.

SCORPIO [Khullar et al. 2013a] recruited 1978 patients with $\mathrm{OAB}$ and showed statistically significant improvement with 50 and $100 \mathrm{mg}$ mirabegron in both the measures. Although improvement was also seen in the tolterodine $4 \mathrm{mg} \mathrm{ER}$ arm, it was not statistically significant. Significant improvement was also seen in mean number of urgency episodes and mean voided volume with mirabegron $50 \mathrm{mg}$ compared with placebo.

ARIES enrolled 1328 patients with $\mathrm{OAB}$, and significant improvement was seen in both coprimary endpoints, along with mean level of urgency, mean urgency incontinence episodes per $24 \mathrm{~h}$, and mean nocturia episodes [Nitti et al. 2013a].

CAPRICORN included 1306 patients who were randomized to placebo, mirabegron $25 \mathrm{mg}$, or mirabegron $50 \mathrm{mg}$ [Herschorn et al. 2013]. Mean reductions in incontinence episodes were 1.36 and 1.38 for mirabegron 25 and $50 \mathrm{mg}$, compared with 0.96 for the placebo group. Mean reductions in micturitions per $24 \mathrm{~h}$ were 1.65 and 1.60 for mirabegron 25 and $50 \mathrm{mg}$, respectively (1.18 for placebo). Mirabegron $50 \mathrm{mg}$ demonstrated significantly greater improvements versus placebo in mean volume voided/micturition, and this was not seen for mirabegron $25 \mathrm{mg}$ [Herschorn et al. 2013].

Pooled analysis of the data from the above trials reviewed outcomes of 3542 patients randomized between placebo, mirabegron 50, and mirabegron $100 \mathrm{mg}$ [Nitti et al. 2013b]. This showed the reduction in mean number of incontinence episodes per $24 \mathrm{~h}$ after 12 weeks of therapy was $-1.10,-1.49$, and -1.50 , respectively. The equivalent reductions for number of micturitions per $24 \mathrm{~h}$ were $-1.20,-1.75$, and -1.74 [Nitti et al. 2013b]. The higher dose did not appear to achieve additional benefit. The active doses also showed benefits in 'dry rates' (zero incontinence episodes per $24 \mathrm{~h}$ ), at $44.1 \%$ (mirabegron $50 \mathrm{mg}$ ) and $46.4 \%(100 \mathrm{mg}$ ) compared with $37.8 \%$ for placebo [Nitti et al. 2013b]. Statistically significant change in nocturia was seen, but the extent of clinical benefit is arguable $(-0.55$ voids per night for the active compound, -0.42 for placebo). Significant difference relative to placebo in these parameters was seen at 4 weeks.

Mirabegron $25 \mathrm{mg}$ and mirabegron $50 \mathrm{mg}$ were also shown to be effective in older patients with OAB ( $>65$ or $>75$ years), demonstrating improvements in the primary endpoints [Wagg et al. 2014].

Considering that antimuscarinic medications have long been the primary drug therapy for $\mathrm{OAB}$, post hoc subgroup analysis looked at the effectiveness in treatment-naive patients and those who had previously discontinued antimuscarinic treatment (either from lack of efficacy, or due to difficulty tolerating the medication) [Khullar et al. 2013b]. Response to mirabegron in terms of primary outcome measures was not affected by antecedent medication exposure (for those who discontinued due to poor efficacy), but it did significantly impact on response to the antimuscarinic active comparator. The placebo effect was found to be greater in the treatment-naive patients. Further information on this will be given by the BEYOND study [ClinicalTrials.gov identifier: NCT01638000], which studied 1870 patients who were not satisfied by antimuscarinic therapy 
(on a treatment satisfaction Likert scale), and randomized them to either mirabegron $50 \mathrm{mg}$ or solifenacin $5 \mathrm{mg}$.

Overall, onset of response appears to be achieved for efficacy and quality of life measures at 1 month [Chapple et al. 2014]. Long-term efficacy was evaluated in the TAURUS study, which was a randomized, double-blind parallel group phase III trial, using mirabegron at doses of 50 or $100 \mathrm{mg}$ and tolterodine $4 \mathrm{mg}$ ER as active comparator [Chapple et al. 2013c]. In this trial, 2444 patients were recruited. Efficacy endpoints were secondary measures, with improvements in OAB symptoms for both doses ( 50 and $100 \mathrm{mg}$ ) seen by 1 month, using various measures, and maintained throughout the follow-up period

Health-related quality of life (HRQL) and treatment satisfaction were assessed in the mirabegron trials using various validated $\mathrm{OAB}$-specific and general scales, such as the overactive bladder questionnaire [Coyne et al. 2002], the patient perception of bladder condition [Coyne et al. 2006], and a treatment satisfaction visual analog scale. Significant improvement was demonstrated from baseline to final visit in these parameters of $\mathrm{HRQL}$ in all three of the main phase III studies.

In the DRAGON study [Chapple et al. 2013b], International Consultation on Incontinence Questionnaire-Overactive Bladder (ICIQ-OAB) and ICIQ-OAB quality of life questionnaires were used. Patient-reported benefit was also evaluated, with the question 'has the treatment been of any benefit to you?' The percentage of responders was $59.0 \%, 65 \%, 65.8 \%$, and $70.8 \%$ for $25,50,100$, and $200 \mathrm{mg}$ mirabegron, respectively compared with $51 \%$ for placebo and $55 \%$ of the tolterodine group.

The studies included male patients, who generally made up between one quarter and one third of the study population in most of the reported studies, but the analyses did not separate findings according to sex.

\section{Safety and tolerability}

Mirabegron appears to have acceptable safety and tolerability in all the reported trials. In the BLOSSOM trial [Chapple et al. 2013b], the incidence of treatment-emergent adverse effects (TEAEs) was $39.2 \%$ with mirabegron compared with $36.4 \%$ and $48.4 \%$ for placebo and tolterodine, respectively. Most of the adverse effects were minor or moderate in severity. The most commonly reported side effects were gastrointestinal disorders $(13.8 \%)$, followed by headache $(6.9 \%)$. Dizziness and palpitations were more common in mirabegron groups than the tolterodine group. The discontinuation rates due to adverse effects were $4.6 \%$ and $7.7 \%$ for the mirabegron groups compared with $1.5 \%$ in the placebo group and $3.1 \%$ in the tolterodine group.

In the DRAGON trial [Chapple et al. 2013b], the incidence of serious adverse events was reported as less than $2 \%$ of patients across the treatment groups. The most common side effects reported were again gastrointestinal $(7.2-8.3 \%$ with mirabegron versus $5.3 \%$ with placebo), including constipation, dry mouth, dyspepsia, and nausea. Incidence of dry mouth was higher with tolterodine $(3.5 \%)$ than mirabegron $(1.8-3.0 \%)$. A dose-dependent small rise in pulse rate was also noted with mirabegron; this was not associated with any cardiovascular side effect, with no difference found in electrocardiogram parameters and blood pressure across the treatment groups. Discontinuation due to side effects was low, at $3.0 \%$ for placebo $(3.0 \%), 2.4$ $5.3 \%$ for mirabegron and $1.2 \%$ for tolterodine. There were no clinically significant episodes of acute retention observed with mirabegron.

Pooled safety data from SCORPIO, ARIES, and CAPRICORN showed that the overall incidence of TEAEs was similar across the treatment groups and there was no evidence of a dose-response relationship among the mirabegron treatment groups for overall rates of TEAEs (mirabegron $25 \mathrm{mg}$ $48.6 \%$, mirabegron $50 \mathrm{mg} 47.1 \%$, mirabegron 100 mg $43.3 \%$, total mirabegron $46.0 \%$, placebo

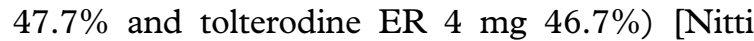
et al. 2013b]. The most common side effects noted in the mirabegron groups were hypertension $(7.3 \%)$, nasopharyngitis $(3.4 \%)$, and urinary tract infection (3.0\%). Dry mouth occurred more commonly in the tolterodine group $(2.0 \%$ for the total mirabegron groups versus $2.1 \%$ for placebo and $10.1 \%$ for the tolterodine group). The discontinu-

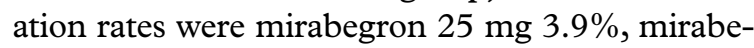

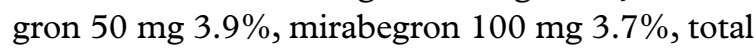
mirabegron $3.8 \%$, placebo $3.3 \%$, and tolterodine ER $4 \mathrm{mg} 4.4 \%$.

In the 12-month TAURUS study, the incidence of TEAEs was similar across the mirabegron $50 \mathrm{mg}$ (59.7\%), mirabegron $100 \mathrm{mg}$ (61.3\%), and 
tolterodine ER $4 \mathrm{mg}$ (62.6\%) groups. Most of the side effects were of mild or moderate severity. The most frequent were hypertension, constipation, and headache, occurring at a similar incidence across treatment groups, and dry mouth. Dry mouth had a higher incidence in the tolterodine group $8.6 \%$ versus mirabegron 2.3-2.8\%). Discontinuations due to adverse events were comparable across treatment groups, occurring in $6.4 \%, 5.9 \%$, and $6.0 \%$ of patients receiving mirabegron $50 \mathrm{mg}$, mirabegron $100 \mathrm{mg}$, and tolterodine ER $4 \mathrm{mg}$, respectively.

In older patients, $49 \%$ of placebo patients and $55 \%$ on active compound reported a TEAE. The three main adverse effects on active compound were hypertension, nasopharyngitis, and urinary tract infection [Wagg et al. 2014]. Dry mouth and constipation did not differ from placebo.

For men, in whom bladder outlet obstruction might be a feature due to benign prostate enlargement, the possibility of impairing voiding function as a consequence of administering medications to aid urine storage has to be considered. A urodynamic safety study was undertaken in 200 men receiving mirabegron 50 or $100 \mathrm{mg}$ or placebo for 12 weeks [Nitti et al. 2013c]. Maximum flow rate and detrusor pressure at maximum flow were not significantly impaired by active treatment. A small increase in postvoid residual was seen for mirabegron $100 \mathrm{mg}$. Acute urinary retention occurred in one man on placebo and one on mirabegron $100 \mathrm{mg}$. The proportion of patients experiencing at least $150 \mathrm{ml}$ change from baseline in postvoid residual volume was lower in the mirabegron groups compared with tolterodine: mirabegron $25 \mathrm{mg}(0 \%)$, mirabegron $50 \mathrm{mg}(0.3 \%)$, mirabegron $100 \mathrm{mg}(0.4 \%)$, placebo $(0.7 \%)$, and tolterodine ER $4 \mathrm{mg}(0.8 \%)$ in the pooled analysis of the phase III trials [Nitti et al. 2013b].

Mirabegron was shown not to raise intraocular pressure after treatment with $100 \mathrm{mg}$ daily for 8 weeks in healthy volunteers [Novack et al. 2013], which is advantageous when considering that closed-angle glaucoma is a contraindication to antimuscarinic therapy.

\section{Combination therapy}

Management of LUTS is increasingly reliant on combination pharmaceutical therapy, and the introduction of a new drug class for $\mathrm{OAB}$ offers further opportunities for combinations aiming to increase efficacy or reduce side effects. The
SYMPHONY study [Abrams et al. 2014] was a dose-ranging phase II study using a range of permutations combining mirabegron with solifenacin. Several combination doses achieved greater improvements in mean voided volume, micturition frequency, and urgency than solifenacin monotherapy. The BESIDE study [ClinicalTrials.gov identifier: NCT01908829] has recently completed recruitment, and was designed to see if adding mirabegron to an antimuscarinic treatment (solifenacin) will be more effective in controlling incontinence than when using the antimuscarinic treatment alone.

In male LUTS, combinations of antimuscarinic medication and $\alpha$-adrenergic blockers are routinely used in refractory cases (for example, solifenacin and tamsulosin) (van Kerrebroeck et al. 2013]. Combining mirabegron with $\alpha$-adrenergic blockers is likely to be considered in developing the therapeutic area. Efficacy assessments for such combinations have recently been reported in men receiving mirabegron with tamsulosin $(0.2 \mathrm{mg})$, in whom the OAB Symptom Score fell by -2.21 for the combination group and by -0.87 in the tamsulosin monotherapy group [Ichihara et al. 2015]. The safety aspects of combining mirabegron with tamsulosin have previously been reported in a separate study [van Gelderen et al. 2014].

\section{Conclusion}

Mirabegron is a first-in-class $\beta_{3}$ agonist for treatment of OAB in women or men, which appears to have good efficacy and tolerability. It can be used in patients who have discontinued antimuscarinic therapy, or who have contraindications for antimuscarinics. Development of combination therapies may further extend the management options in $\mathrm{OAB}$ in the future.

\section{Funding}

This research received no specific grant from any funding agency in the public, commercial, or notfor-profit sectors.

\section{Conflict of interest statement}

Marcus J. Drake: Advisory boards, research and speaker bureaux for Allergan, Astellas and Ferring. Monika Vij has no CoI.

\section{References}

Abrams, P., Cardozo, L., Fall, M., Griffiths, D., Rosier, P., Ulmsten, U. et al. (2002) The 
standardisation of terminology of lower urinary tract function: report from the Standardisation Subcommittee of the International Continence Society. Neurourol Urodyn 21: 167-178.

Abrams, P., Kelleher, C., Staskin, D., Griffiths, D., Rosier, P., Ulmsten, U. et al. (2014) Combination treatment with mirabegron and solifenacin in patients with overactive bladder: efficacy and safety results from a randomised, double-blind, dose-ranging, phase 2 study (Symphony). Eur Urol 67: 577-588.

Aizawa, N., Igawa, Y., Nishizawa, O. and Wyndaele, J. (2010) Effects of CL316,243, a $\beta_{3}$-adrenoceptor agonist, and intravesical prostaglandin E2 on the primary bladder afferent activity of the rat. Neurourol Urodyn 29: 771-776.

Chapple, C., Amarenco, G., Lopez Aramburu, M., Everaert, K., Liehne, J., Lucas., M. et al. (2013a) A proof-of-concept study: mirabegron, a new therapy for overactive bladder. Neurourol Urodyn 32: 1116-1122.

Chapple, C., Dvorak, V., Radziszewski, P., Van Kerrebroeck, P., Wyndaele, J., Bosman, B. et al. (2013b) A phase II dose-ranging study of mirabegron in patients with overactive bladder. Int Urogynecol $\mathcal{F}$ 24: 1447-1458.

Chapple, C., Kaplan, S., Mitcheson, D., Klecka, J., Cummings, J., Drogendijk, T. et al. (2013c) Randomized double-blind, active-controlled phase 3 study to assess 12-month safety and efficacy of mirabegron, a $\beta$ (3)-adrenoceptor agonist, in overactive bladder. Eur Urol 63: 296-305.

Chapple, C., Khullar, V., Gabriel, Z., Muston, D., Bitoun, C. and Weinstein, D. (2008) The effects of antimuscarinic treatments in overactive bladder: an update of a systematic review and meta-analysis. Eur Urol 54: 543-562.

Chapple, C., Nitti, V., Khullar, V., Wyndaele, J., Herschorn, S., van Kerrebroeck, P. et al. (2014) Onset of action of the $\beta_{3}$-adrenoceptor agonist, mirabegron, in Phase II and III clinical trials in patients with overactive bladder. World f Urol 32: 1565-1572.

Coyne, K., Matza, L., Kopp, Z. and Abrams, P. (2006) The validation of the patient perception of bladder condition (PPBC): a single-item global measure for patients with overactive bladder. Eur Urol 49: 1079-1086.

Coyne, K., Revicki, D., Hunt, T., Corey, R., Stewart, W., Bentkover, J. et al. (2002) Psychometric validation of an overactive bladder symptom and health-related quality of life questionnaire: the OAB-q. Qual Life Res 11: 563-574.

Coyne, K., Sexton, C., Thompson, C., Milsom, I., Irwin, D., Kopp, Z. et al. (2009) The prevalence of lower urinary tract symptoms (LUTS) in the USA, the UK and Sweden: results from the Epidemiology of LUTS (EpiLUTS) study. BFU Int 104: 352-360.

Coyne, K., Wein, A., Nicholson, S., Kvasz, M., Chen, C. and Milsom, I. (2014) Economic burden of urgency urinary incontinence in the United States: a systematic review. F Manag Care Pharm 20: 130-140.

Dickinson, J., Lewand, M., Sawamoto, T., Krauwinkel, W., Schaddelee, M., Keirns, J. et al. (2013) Effect of renal or hepatic impairment on the pharmacokinetics of mirabegron. Clin Drug Invest 33: 11-23.

Drake, M. (2014) Do we need a new definition of the overactive bladder syndrome? ICI-RS 2013. Neurourol Urodyn 33: 622-624.

Herschorn, S., Barkin, J., Castro-Diaz, D., Frankel, J., Espuna-Pons, M., Gousse, A. et al. (2013) A phase III, randomized, double-blind, parallel-group, placebo-controlled, multicentre study to assess the efficacy and safety of the $\beta$ (3) adrenoceptor agonist, mirabegron, in patients with symptoms of overactive bladder. Urology 82: 313-320.

Ichihara, K., Masumori, N., Fukuta, F., Tsukamoto, T., Iwasawa, A. and Tanaka, Y. (2015) A randomized controlled study of the efficacy of tamsulosin monotherapy and its combination with mirabegron for overactive bladder induced by benign prostatic obstruction. F Urol 193: 921-926.

Igawa, Y., Aizawa, N. and Homma, Y. (2010) Beta3adrenoceptor agonists: possible role in the treatment of overactive bladder. Korean $\mathcal{F}$ Urol 51: 811-818.

Kanai, A., Wyndaele, J., Andersson, K., Fry, C., Ikeda, Y., Zabbarova, I. et al. (2011) Researching bladder afferents-determining the effects of $\beta$ (3)adrenergic receptor agonists and botulinum toxin type-A. Neurourol Urodyn 30: 684-691.

Kaplan, S., Roehrborn, C., Abrams, P., Chapple, C., Bavendam, T. and Guan, Z. (2011) Antimuscarinics for treatment of storage lower urinary tract symptoms in men: a systematic review. Int $\mathcal{F}$ Clin Pract 65: 487-507.

Kashyap, M. and Tyagi, P. (2013) The pharmacokinetic evaluation of mirabegron as an overactive bladder therapy option. Expert Opin Drug Metab Toxicol 9: 617-627.

Khullar, V., Amarenco, G., Angulo, J., Cambronero, J., Høye, K., Milsom, I. et al. (2013a) Efficacy and tolerability of mirabegron, a $\beta$ (3)-adrenoceptor agonist, in patients with overactive bladder: results from a randomised European-Australian phase 3 trial. Eur Urol 63: 283-295.

Khullar, V., Cambronero, J., Angulo, J., Wooning, M., Blauwet, M., Dorrepaal, C. et al. (2013b) Efficacy of mirabegron in patients with and without prior antimuscarinic therapy for overactive bladder: a post 
hoc analysis of a randomized European-Australian Phase 3 trial. BMC Urol 13: 45.

Krauwinkel, W., Dickinson, J., Schaddelee, M., Meijer, J., Tretter, R., van de Wetering, J. et al. (2014) The effect of mirabegron, a potent and selective $\beta 3$-adrenoceptor agonist, on the pharmacokinetics of CYP2D6 substrates desipramine and metoprolol. Eur F Drug Metab Pharmacokinet 39: 43-52.

Kullmann, F., Downs, T., Artim, D., Limberg, B., Shah, M., Contract, D. et al. (2011) Urothelial beta-3 adrenergic receptors in the rat bladder. Neurourol Urodyn 30: 144-150.

Lee, J., Moy, S., Meijer, J., Krauwinkel, W., Sawamoto, T., Kerbusch, V. et al. (2013a) Role of cytochrome p450 isoenzymes 3A and 2D6 in the in vivo metabolism of mirabegron, a $\beta 3$-adrenoceptor agonist. Clin Drug Invest 33: 429-440.

Lee, J., Zhang, W., Moy, S., Krauwinkel, W., Sawamoto, T., Kerbusch, V. et al. (2013b) Effects of food intake on the pharmacokinetic properties of mirabegron oral controlled-absorption system: a single-dose, randomized, crossover study in healthy adults. Clin Ther 35: 333-341.

Limberg, B., Andersson, K., Aura Kullmann, F., Burmer, G., de Groat, W. and Rosenbaum, J. (2010) $\beta$-Adrenergic receptor subtype expression in myocyte and non-myocyte cells in human female bladder. Cell Tissue Res 342: 295-306.

Lucas, M., Bosch, R., Burkhard, F., Cruz, F., Madden, T., Nambiar, A. et al. (2012) EAU Guidelines on Assessment and Nonsurgical Management of Urinary Incontinence. Eur Urol 62: 1130-1142.

Maman, K., Aballea, S., Nazir, J., Desroziers, K., Neine, M., Siddiqui, E. et al. (2014) Comparative efficacy and safety of medical treatments for the management of overactive bladder: a systematic literature review and mixed treatment comparison. Eur Urol 65: 755-765.

Milsom, I., Coyne, K., Nicholson, S., Kvasz, M., Chen, C. and Wein, A. (2014) Global prevalence and economic burden of urgency urinary incontinence: a systematic review. Eur Urol 65: 79-95.

Moro, C., Tajouri, L. and Chess-Williams, R. (2013) Adrenoceptor function and expression in bladder urothelium and lamina propria. Urology 81: 211 e1-e7.

Murakami, S., Chapple, C., Akino, H., Sellers, D. and Chess-Williams, R. (2007) The role of the urothelium in mediating bladder responses to isoprenaline. BfU Int 99: 669-673.

Nitti, V., Auerbach, S., Martin, N., Calhoun, A., Lee, M. and Herschorn, S. (2013a) Results of a randomized phase III trial of mirabegron in patients with overactive bladder. F Urol 189: 1388-1395.

Nitti, V., Khullar, V., van Kerrebroeck, P., Herschorn, S., Cambronero, J., Angulo, J. et al. (2013b) Mirabegron for the treatment of overactive bladder: a prespecified pooled efficacy analysis and pooled safety analysis of three randomised, doubleblind, placebo-controlled, phase III studies. Int $\mathcal{f}$ Clin Pract 67: 619-632.

Nitti, V., Rosenberg, S., Mitcheson, D., He, W., Fakhoury, A. and Martin, N. (2013c) Urodynamics and safety of the $\beta_{3}$-adrenoceptor agonist mirabegron in males with lower urinary tract symptoms and bladder outlet obstruction. F Urol 190: 1320-1327.

Novack, G., Lewis, R., Vogel, R., Sheth, N., Swearingen, D., Rasmussen, S. et al. (2013) Randomized, double-masked, placebo-controlled study to assess the ocular safety of mirabegron in healthy volunteers. F Ocul Pharmacol Ther 29: 674680 .

Ochodnicky, P., Uvelius, B., Andersson, K. and Michel, M. (2013) Autonomic nervous control of the urinary bladder. Acta Physiol (Oxf) 207: 16-33.

Otsuka, A., Shinbo, H., Matsumoto, R., Kurita, Y and Ozono, S. (2008) Expression and functional role of $\beta$-adrenoceptors in the human urinary bladder urothelium. Naunyn Schmiedebergs Arch Pharmacol 377: 473-481.

Sadananda, P., Drake, M., Paton, J. and Pickering, A. (2013) A functional analysis of the influence of $\beta 3$-adrenoceptors on the rat micturition cycle. $\mathcal{F}$ Pharmacol Exp Ther 347: 506-515.

Takasu, T., Ukai, M., Sato, S., Matsui, T., Nagase, I., Maruyama, T. et al. (2007) Effect of (R)-2-(2aminothiazol-4-yl)-4'-\{2-[(2-hydroxy-2-phenylethyl) amino] ethyl $\}$ acetanilide (YM178), a novel selective beta3-adrenoceptor agonist, on bladder function. $\mathcal{F}$ Pharmacol Exp Ther 321: 642-647.

van Gelderen, M., Tretter, R., Meijer, J., Dorrepaal, C., Gangaram-Panday, S., Brooks, A. et al. (2014) Absence of clinically relevant cardiovascular interaction upon add-on of mirabegron or tamsulosin to an established tamsulosin or mirabegron treatment in healthy middle-aged to elderly men. Int $\mathcal{F}$ Clin Pharmacol Ther 52: 693-701.

van Kerrebroeck, P., Chapple, C., Drogendijk, T., Klaver, M., Sokol, R., Speakman, M. et al. (2013) Combination therapy with solifenacin and tamsulosin oral controlled absorption system in a single tablet for lower urinary tract symptoms in men: efficacy and safety results from the randomised controlled NEPTUNE trial. Eur Urol 64: 1003-1012.

Wagg, A., Cardozo, L., Nitti, V., Castro-Diaz, D., Auerbach, S., Blauwet, M. et al. (2014) The 
Visit SAGE journals online http://tau.sagepub.com

@SAGE journals efficacy and tolerability of the $\beta 3$-adrenoceptor agonist mirabegron for the treatment of symptoms of overactive bladder in older patients. Age Ageing 43: 666-675.

Wagg, A., Compion, G., Fahey, A and Siddiqui, E. (2012) Persistence with prescribed antimuscarinic therapy for overactive bladder: a UK experience. $B \mathcal{H}$ Int 110: 1767-1774.
Woods, M., Carson, N., Norton, N., Sheldon, J. and Argentieri, T. (2001) Efficacy of the $\beta 3$-adrenergic receptor agonist CL-316243 on experimental bladder hyperreflexia and detrusor instability in the rat. $\mathcal{F}$ Urol 166: 1142-1147.

Yamaguchi, O. and Chapple, C. (2007) B3adrenoceptors in urinary bladder. Neurourol Urodyn 26: 752-756. 